\title{
A case report and a literature review:A challenging case of Chronic tubal ectopic pregnancy
}

\section{Introduction}

An ectopic pregnancy is the implantation of a fertilized egg outside the uterine endometrial cavity, in which $95 \%$ of cases, implants in the fallopian tube, commonly in the ampullary region. ${ }^{1}$ Clinically presents with amenorrhea, abdominal pain and abnormal vaginal bleeding. ${ }^{2}$ Ectopic pregnancy can be managed either medically or surgically depending on patients clinical presentation, ultrasound, biochemical and hematological findings. ${ }^{3}$ Chronic ectopic pregnancy is a rare diagnostic challenging condition which is associated with non-specific clinical signs and symptoms. In most of the cases, the serum Bhcg level is either very low or negative. ${ }^{2}$

\section{Case report}

A 27-year-old Omani female, previously healthy, presented to the Emergency Department with a gradual onset of right lower abdominal pain, minimal vaginal bleeding and offensive vaginal discharge for two days, associated with fever, nausea and vomiting for one day. Her obstetric history was notable for recent right ectopic pregnancy which was treated medically by methotrexate (in view Bhcg being 400) three months ago, with previous two uneventful full term normal vaginal deliveries. Clinical examination revealed afebrile patient with right lower abdominal tenderness, no palpable masses or adnexal tenderness. Her serum Bhcg level was recorded as 4.48

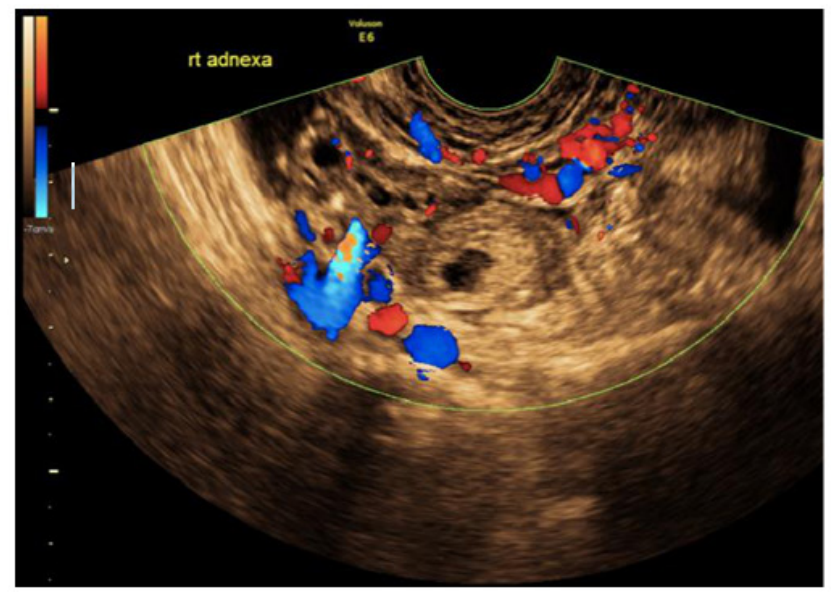

\author{
Volume 10 Issue I - 202I
}

\author{
Nourah Al Kindi, Fatima Al Shalabi, Shabana \\ Kapadia, Asma Jan \\ Obstetrics and Gynecology Residency program, Al Ain hospital, \\ United Arab Emirates
}

Correspondence: Nourah Ali Alkindi, Medical Resident, Obstetrics and Gynecology Residency program, Al Ain hospital, United Arab Emirates, Tel 0097I56I052232,

Email alshaeer105@gmail.com or nouralkindi@seha.ae

Received:Sepetember 28, 2020 | Published: Janauary 05, 2021

IU/L, C-reactive protein elevated to $47 \mathrm{mg} / \mathrm{L}$ with normal white cell count level and dropping hemoglobin by almost 2 grams noted in the past one month. An urgent pelvic Ultrasound scan showed an empty uterus with right heterogenous adnexal mass around $1.6 \times 1.3 \mathrm{~cm}$ with minimal free fluid in the pouch of Douglas and bilateral ovarian cysts (Figure 1).

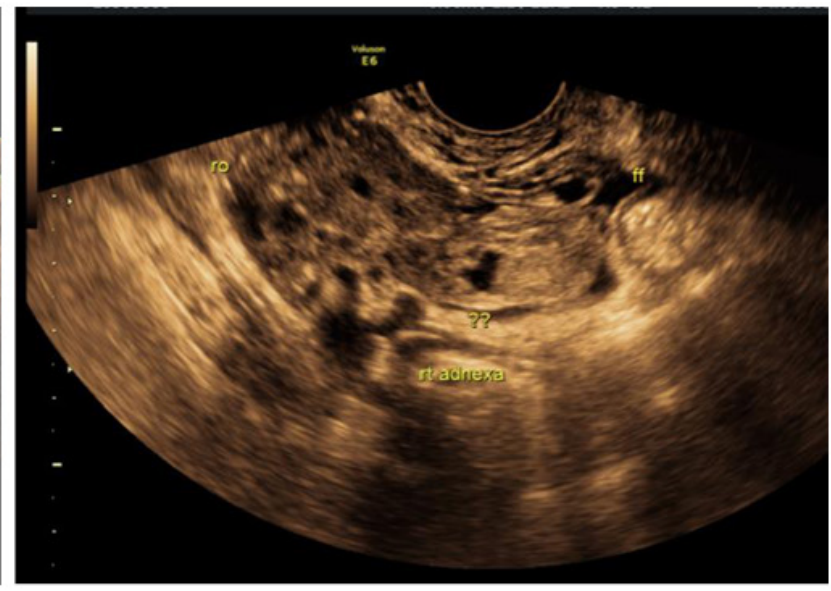

Figure I Patient was evaluated by Surgical team and acute appendicitis was excluded after CT abdomen and pelvis.

Initially, Pelvic inflammatory disease (PID) was suspected, the patient was started on intravenous antibiotics,screened for sexually transmitted infections (which were negative). Furthermore, she had additional blood tests, CA 125 (slightly elevated to 40 units/ml) and other tumor markers (CEA, AFP, Ca19-9, all within the normal limits). Patient underwent uncomplicated diagnostic laparoscopy for worsening right abdominal pain, had right salpingectomy in view of dilated right fallopian tube with a notable mass. Histopathology confirmed chronic right ectopic pregnancy with no evidence of gestational trophoblastic disease or fetal somatic tissue. At two weeks follow up, the patient had an uneventful recovery from surgery, with her subsequent post-operative serum BhCG levels undetectable $<0.5$ IU/L.

\section{Discussion}

Ectopic pregnancy has a wide range of presentation from acute hemoperitoneum to chronic ectopic pregnancy (CEP). Chronic ectopic pregnancy is extremely rare in developed countries, due to the presence of early-pregnancy care service. ${ }^{1}$ It has non-classical symptoms and limitations in diagnosis. CEP occurs when trophoblastic tissue invades the implanted structure, causing a protracted destruction at the site of attachment, resulting in repeated rupture and minor bleeding. Over 
time, a haematocele is formed, leading to an inflammatory reaction and the generation of chronic pelvic adhesions which resemble a complex pelvic mass can be seen in diagnostic imgaing. Serum human chorionic gonadotropin (BhCG) typically low or negative in CEP as the chorionic villi are usually sparse. ${ }^{1}$ Diagnostic imaging like transvaginal ultrasound may plays a role in diagnosis of CEP preoperatively, as it shows an extrauterine heterogeneous mass with low impedance color flow doppler on its surface., Exploratory laparoscopy remains the gold standard modality for diagnosing and managing ectopic and chronic ectopic pregnancies. ${ }^{3}$

\section{Conclusion}

Chronic ectopic pregnancy carries a high risk of morbidity and mortality in view of its rare challenging and misleading condition. Accurate diagnosis becomes possible only after exploratory laparoscopy and histopathological examination..$^{2-4}$

\section{Acknowledgments}

None.

\section{Conflicts of interest}

The author declares that there is no conflict of interest to disclose.

\section{Funding}

None.

\section{References}

1. O'Neill D, Pounds R, Vella J, et al. The diagnostic conundrum of chronic ectopic pregnancy: A case report. Case Rep Womens Health. 2018;20:e00086.

2. Nina VR, Maria B, Erling E. A Case of Chronic Ectopic Pregnancy Manifested by Rectal Bleeding. Case Reports in Obstetrics and Gynecology. 2017:3.

3. Drakopoulos P, Pluchino N, Yaron M, et al. Chronic tubal ectopic pregnancy: a rare but challenging diagnosis. BMJ Case Rep. 2014.

4. Nacharaju M, Vellanki VS, Gillellamudi SB, et al. A rare case of chronic ectopic pregnancy presenting as large hematosalpinx. Clin Med Insights Reprod Health. 2014;8:1-4. 